\title{
Processing of Y-Doped Ceria Film by Doctor Blade Method
}

\author{
Shinichi UCHIDA, Soichiro SAMESHIMA and Yoshihiro HIRATA \\ Department of Applied Chemistry and Chemical Engineering, Faculty of Engineering, Kagoshima University, \\ 1-21-40, Korimoto, Kagoshima-shi 890-0065 \\ ドクターブレード法によるイットリア固溶セリア膜のプロセッシング \\ 内田真一·鮫島宗一郎・平田好洋 \\ 鹿児島大学工学部応用化学工学科, 890-0065 鹿児島市郡元 1-21-40
}

\begin{abstract}
An Y-doped ceria powder with composition of $\mathrm{Ce}_{0.8} \mathrm{Y}_{0.2} \mathrm{O}_{1.9}$ was prepared by heating oxalate coprecipitate at $600^{\circ} \mathrm{C}$ in air. The calcined powder was milled with $\alpha$-alumina ball of $3 \mathrm{~mm}$ diameter. The Y-doped ceria films were formed by doctor blade method applied to aqueous suspensions of $23-35$ vol\% Y-doped ceria powder with a median size $0.9 \mu \mathrm{m}$. The thickness of the formed films depended strongly on the blade clearance. The density of the sintered films was affected by the solid content of the suspension. This result was discussed with the sintering model associated with the shortest distance between particles. Upon heating, a lot of closed pores were formed at the initial stage of sintering. The densification process and microstructures of the films were discussed in relation to the properties of powder compacts consolidated by isostatic pressing.
\end{abstract} [Received July 31, 2000; Accepted November 13, 2000]

Key-words : Yttria-doped ceria, Doctor blade, Suspension, Closed pore, Anisotropic shrinkage

\section{Introduction}

The operation temperature of the solid oxide fuel cell (SOFC) depends significantly on the ionic conductivity of the solid electrolyte used. The development of highly conductive solid electrolyte and the fabrication of dense thin film of solid electrolyte are the effective strategy to operate SOFC at low temperatures. The decrease in the operating temperature allows the long life time of SOFC and expands the choice of constituent materials such as electrodes or metal gas separator. The following processings have been reported in the preparation of thin solid electrolyte: slurry coating, ${ }^{1)}$ plasma sputtering, ${ }^{2)}$ chemical vapor deposition (CVD), 3) sol-gel method, ${ }^{4)}$ and electrochemical vapor deposition (EVD) .5) CVD process is applied to the formation of films with simple chemical compositions because of a strict control of vapor pressures of precursors. The cost of CVD process is high as compared with that of powder processing. Sol-gel processing with liquid precursors can produce the films with complicated chemical compositions. However, a lot of time, labor and energy are used to make crack-free films by the repeated sequence of coating-drying-firing. On the other hand, doctor blade method is a low cost processing to produce the continuous films with constant thickness above $3 \mu \mathrm{m}$. $^{6}$ The electrolyte for the planar type SOFC is generally formed by the tape casting of yttria-stabilized zirconia (YSZ) powder. A low temperature operation of SOFC $\left(\sim 800^{\circ} \mathrm{C}\right)$ is expected when the YSZ film becomes thinner than $40 \mu \mathrm{m}$. ${ }^{7)}$ For the tublar type cell, dense YSZ film is produced by the EVD method. This paper reports the processing and microstructures of Y-doped ceria films by the doctor blade method. The solid electrolyte films should be dense to separate fuel gas and air. A good agreement of the thermal expansion coefficients between dense electrolyte film and porous electrodes is also required to avoid the fracture by the cyclic heating. Of course, increase of the ionic conductivity of electrolyte film enhances the efficiency of electric power of SOFC and leads to the decrease in the operating temperature of SOFC. The oxygen ion conductivity of rare-earth-doped ceria is higher than that of $\mathrm{Y}_{2} \mathrm{O}_{3}$-stabilized zirconia. In this paper, we study the following influences to fabricate crack-free dense Y-doped ceria films by doctor blade method: (1) the key parameters affecting the thickness of as-formed films, (2) drying characteristics of the formed films, and (3) sintering behavior of dried films. Through the measurement of porosity of open and closed pores, it was found that the densification behavior of the films (thickness $<500 \mu \mathrm{m}$ ) was different from that of the powder compacts (thickness $\sim 2 \mathrm{~mm}$ ). This result was also discussed in this paper.

\section{Experimental procedure}

The $\mathrm{Ce}_{0.8} \mathrm{Y}_{0.2} \mathrm{O}_{1.9}$ powder (shoten as YDC) was prepared by calcining the oxalate coprecipitate at $600^{\circ} \mathrm{C}$. The detailed powder preparation is reported in our previous papers. ${ }^{8), 9)}$ Cerium and yttrium nitrate solutions of $0.2 \mathrm{M}$ were mixed at the molar ratio of $\mathrm{Ce}^{3+} / \mathrm{Y}^{3+}=4 / 1$. The mixed solutions were dropped into the stirred oxalic acid solution of $0.4 \mathrm{M}$. The coprecipitate produced was vacuum-filtrated, washed with double distilled water and dried overnight at $45^{\circ} \mathrm{C}$. Then the oxalate coprecipitate was decomposed at $600^{\circ} \mathrm{C}$ in air to form the oxide solid solution with the valence change from $\mathrm{Ce}^{3+}$ to $\mathrm{Ce}^{4+}$. The calcined powder was milled with $\alpha^{-}$ alumina ball of $3 \mathrm{~mm}$ in diameter in polyethylene container for $24 \mathrm{~h}$. The median size of as-produced powder $(1.9 \mu \mathrm{m})$ was reduced to $0.9 \mu \mathrm{m}$ after the ball-milling. The cumulative particle size distribution was as follows: $0.4 \mu \mathrm{m} / 10 \%, 0.9$ $\mu \mathrm{m} / 50 \%, 2.0 \mu \mathrm{m} / 90 \%$. The alumina content of YDC powder collected after the milling was 0.014 mass $\%{ }^{8}$ ) The true density of YDC powder was calculated to be $6.735 \mathrm{~g} / \mathrm{cm}^{3}$ from the lattice parameter $\left.0.5407 \mathrm{~nm} .{ }^{9}\right)$ The aqueous suspensions of 23-35 vol\% of the milled powder were prepared at $\mathrm{pH} 8.5$ by adding polyacrylic ammonium (dispersant) of $0.25 \mathrm{mg} / \mathrm{m}^{2}$-powder surface and methyl cellulose (binder) of $0.30 \mathrm{mg} / \mathrm{m}^{2}$. The $\mathrm{pH}$ was adjusted with $0.1 \mathrm{M}$-ammonium hydroxide solution. Then, the suspensions were stirred for $24 \mathrm{~h}$. After measurement of the viscosity of the suspension by a cone and plate type viscometer (EHD-type, Tokimec Inc., Tokyo), the suspension was consolidated on polyester sheet by doctor blade (DP-100, Tsugawa Seiki Seisakusho, Tokyo) at a transfer rate of $15 \mathrm{~cm} / \mathrm{min}$. The front blade clearance was controlled in the range of $150-1000 \mu \mathrm{m}$ and the back blade clearance was two times as 
high as the front clearance. The formed films were left at room temperature for $7 \mathrm{~d}$. The dried films were sandwiched in two sintered YSZ plates $(28 \mathrm{~mm} \times 40 \mathrm{~mm} \times 5 \mathrm{~mm}, 33 \mathrm{~g})$ and sintered for $1 \mathrm{~h}$ at $1600^{\circ} \mathrm{C}$ in air. The shrinkage of thickness and length of the films was measured after the sintering. The milled $\mathrm{Ce}_{0.8} \mathrm{Y}_{0.2} \mathrm{O}_{1.9}$ powder was also consolidated by uniaxial pressing ( $49 \mathrm{MPa})$, followed by cold isostastic pressing $(294 \mathrm{MPa})$, and sintered at $900-1600^{\circ} \mathrm{C}$ in air for $4 \mathrm{~h}$. The apparent and bulk densities of the sintered films and powder compacts were measured by the Archimedes method in distilled water. The true density $\left(d_{0}\right)$, apparent density $\left(d_{1}\right)$ and bulk density $\left(d_{2}\right)$ are defined by following equations, respectively,

$$
\begin{aligned}
& d_{0}=\frac{W}{V} \\
& d_{1}=\frac{W}{V+C} \\
& d_{2}=\frac{W}{V+C+O}
\end{aligned}
$$

where $W$ is the weight of dried sample, $V$ the volume of solid, $C$ the volume of closed pores and $O$ the volume of open pores. From Eqs. (1)-(3), $C$ and $O$ were determined by Eqs. (4) and (5) using measured $d_{0}, d_{1}$ and $d_{2}$ values, respectively.

$$
\begin{aligned}
& C=W\left(\frac{1}{d_{1}}-\frac{1}{d_{0}}\right) \\
& O=W\left(\frac{1}{d_{2}}-\frac{1}{d_{1}}\right)
\end{aligned}
$$

The microstructures of Au-sputtered sample were observed by scanning electron microscopy (SEM; SM-300, Topcon Co., Ltd., Japan).

\section{Results and discussion}

\subsection{Forming of YDC films}

Figure 1 shows the apparent viscosity of YDC suspensions. The apparent viscosity in the low shear rate range decreased quickly with the increased shear rate, so the behavior of the suspension systems was identified as pseudoplastic flow. Furthermore, the change in the apparent viscosity of the YDC suspensions became small at the higher shear rate. The above result suggests that in the colloidal suspension there was particle coagulation which was destroyed and dispersed with the increase of shear rate. The increased solid loading resulted in the increase of the viscosity, but the basic property of the suspensions was independent of the solid content. Since the YDC films were formed by doctor blade, shear stress was applied by blade to the suspension on the carrier tape. That is, the coagulated particle clusters are destroyed in the formed films. After the consolidation of suspension, the viscosity of the films increases again because of no shear stress. Figure 2 shows the thickness of YDC green films formed by doctor blade. The thickness of films depended on the clearance of the front blade ${ }^{10)-12)}$ and resulted in half of the blade clearance. No apparent relation was observed between the film thickness and the concentration of the suspensions. The thickness of the films is affected by the packing characteristics of particles during the drying on the polyester sheet.

The volume of solid particles $(V)$ in as-formed film with thickness $H$ and base area $S$ is expressed by Eq. (6),

$$
V=S H x
$$

where $x$ is the concentration (vol\%) of solid particles in the suspension. Similarly, Eq. (7) expresses the volume of solid in the dried film with thickness $h$ and base area $S_{g}$,

$$
V=S_{\mathrm{g}} h y
$$

where $y$ is the packing density (vol\%) of solid particles. Since Eq. (6) is equal to Eq. (7), the following relation is derived.

$$
h=\left(\frac{S}{S_{\mathrm{g}}}\right)\left(\frac{x}{y}\right) H
$$

In this experiment, the films did not shrink in the direction of length. Since the ratio of $S / S_{\mathrm{g}}$ was close to 1 , Eq. (8) was approximated to Eq. (9),

$$
h=\left(\frac{x}{y}\right) H
$$

The slope in Fig. 2 indicates the relation of $(x / y) \sim 0.5$ for the YDC film. In the forming of $\mathrm{PbZr}_{1-x} \mathrm{Ti}_{x} \mathrm{O}_{3}$ film, the ratio was reported to be $\left.0.4 .^{12}\right)$ That is, the packing density $(y)$ of particles in the dried film becomes experimentally twice of the concentration of the suspension $(x)$. Figure 3 shows the relative density of YDC films calcined at $1000^{\circ} \mathrm{C}$ as a function of solid concent of the aqueous suspension. The dotted line represents the $x-y$ relation by Eq. (9). The measured density fitted the prediction derived from the relation in

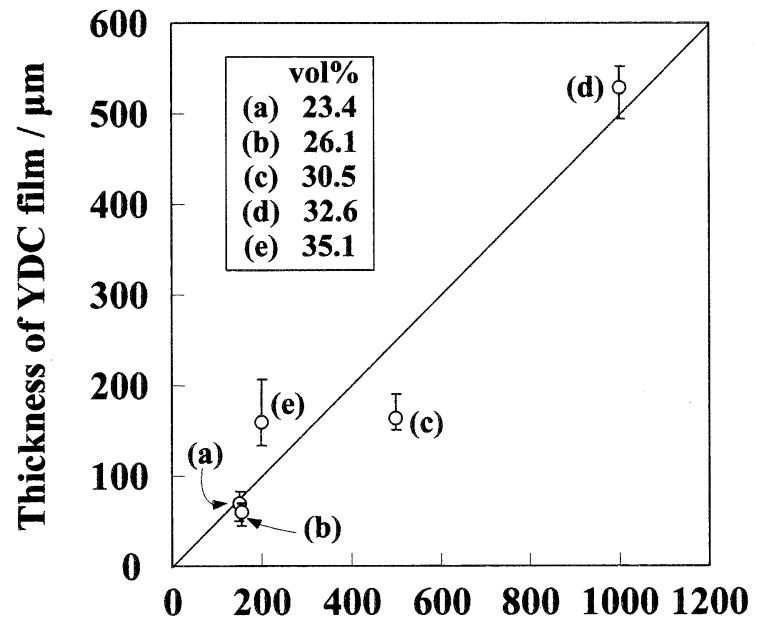

\section{Blade clearance / $\mu \mathrm{m}$}

Fig. 2. Thickness of YDC green films and front blade clearance.
Fig. 1. Apparent viscosity of aqueous YDC suspensions as a func-

tion of shear rate.

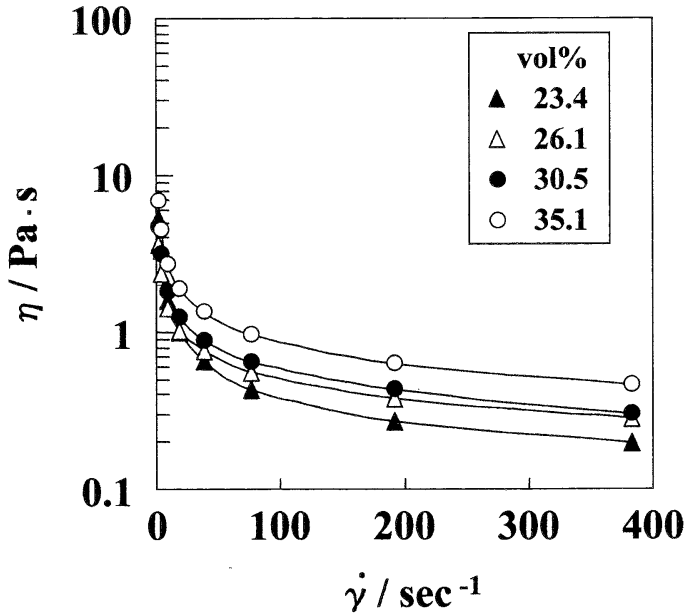




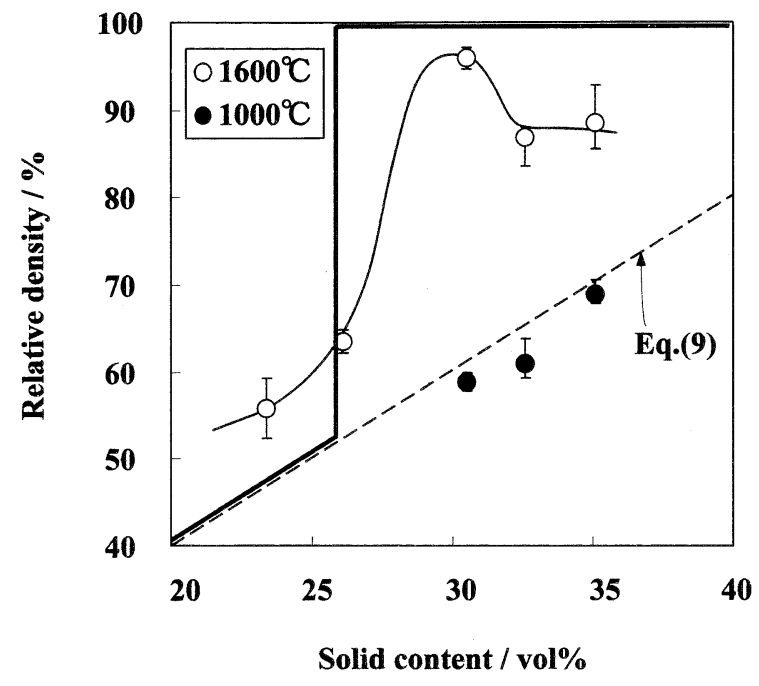

Fig. 3. Dependence of density of heated films on the solid content of the suspension. The dotted line represents Eq. (9) in text. The solid line represents the densification curve based on the sintering model of shortest distance between particles.

\section{Fig. 2.}

\subsection{Sintering}

In Fig. 3, the density of films sintered at $1600^{\circ} \mathrm{C}$ was also plotted. The densification was greatly affected by the solid content of the suspension and promoted at the solid content above $30 \mathrm{vol} \%$. The YDC films formed from the suspensions of 23.4 and 26.1 vol\% solid showed a poor sinterability. On the other hand, the increase in the packing density up to $60 \%$ as shown by the dotted line, caused the high sinterability. This packing density effect is associated with the formation of hierarchical pores in a powder compact. In our previous analysis of the pore size distribution of a powder compact, ${ }^{13)}$ the reduction of the size of particle cluster in a powder compact leads to (1) increase of the green density, (2) increase of the volume of 1 st generation pores formed among primary particles, (3) decrease of the volume of 2 nd generation pores formed among particle clusters, and (4) decrease of the pore size of 2 nd generation pores. The result in Fig. 3 suggests that the influence of the above factors on the sinterability is distinguished between 50 and $60 \%$ packing density. Increase of the solid content of the suspension is effective to reduce the size of hierarchically clustered particles.

To understand more the densification curve in Fig. 3, we consider three types of particle packing (simple cubic (sc), body centered cubic (bcc) and cubic close packing (ccp)) in a particle cluster. Figure 4 shows the unit cell structure of the particle packing. The shortest distance $(D)$ between the surface of two particles with radius $r$ is expressed by Eqs. (10)-(12),

$$
\begin{aligned}
& D=a-2 r(\mathrm{sc}) \\
& D=\frac{\sqrt{3}}{2} a-2 r(\mathrm{bcc}) \\
& D=\frac{\sqrt{2}}{2} a-2 r(\mathrm{ccp})
\end{aligned}
$$

where $a$ is the lattice parameter in Figs. 4(a), (b) and (c). The solid content $\left(V_{\mathrm{P}}\right)$ in an unit cell is expressed by Eq. (13),

$$
V_{\mathrm{P}}=\frac{4}{3} \pi\left(\frac{r}{a}\right)^{3} N
$$
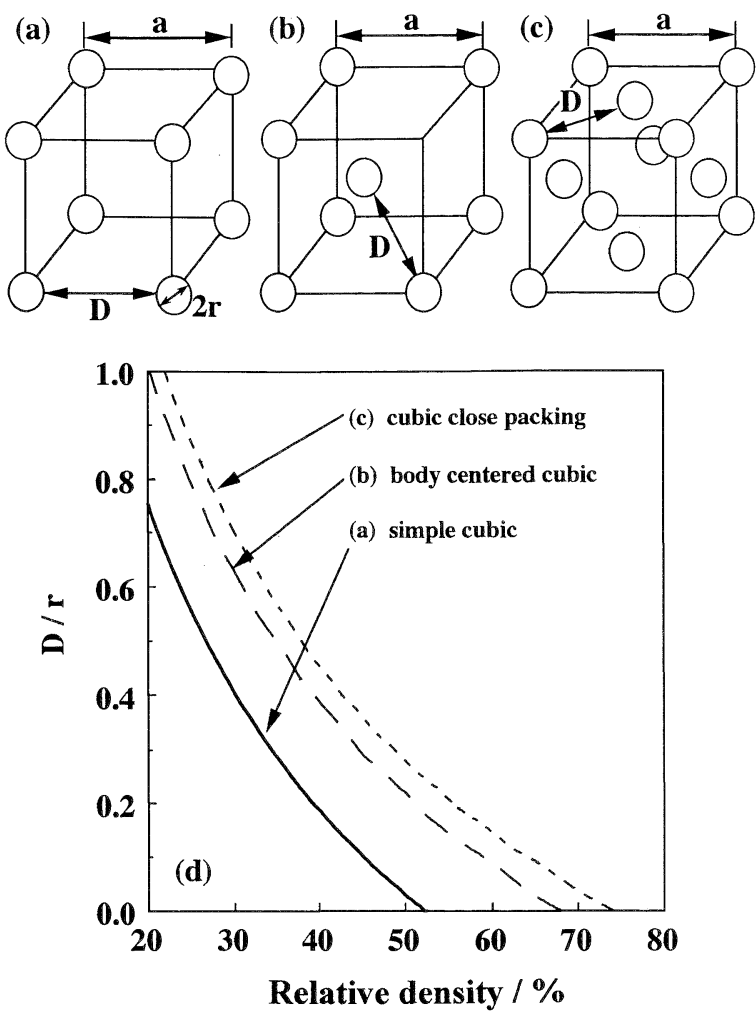

Fig. 4. Particle packing models in a powder compact; (a) simple cubic, (b) body centered cubic and (c) cubic close packing. 4(d) shows the relationship between the solid content in an unit cell (lattice parameter, $a$ ) and the $D / r$ ratio ( $D$ : shortest distance between particles, $r$ : radius of particle).

where $N$ is the number of particles in an unit cell $(N=1$ for sc, $N=2$ for bcc, and $N=4$ for ccp). Figure 4 (d) shows the relationship between the solid content in the unit cell and the $D / r$ ratio calculated by Eqs. (10)-(13). The $D / r$ ratio approaches 0 at $V_{\mathrm{P}}=0.524,0.680$ and 0.741 for the packing structures of sc, bcc and ccp, respectively. The calculation in Fig. 4(d) indicates that the two particles in sc start to contact as the packing density increases to 0.524 where one particle in bcc and ccp is not in contact with another particle. According to the above packing models, no sintering occurs below $52.0 \%$ of packing density because of no contact between the particles. When the packing density increased above $52.0 \%$, densification starts by the sintering of the particles in sc packing. This densification causes the shrinkage of powder compact and leads to contact of the particles in bcc at the relative density of $68.0 \%$. A similar sequence of the contact-sintering-shrinkage of the particles in bcc causes the contact of the particles in ccp. In the above sintering model, densification occurs continuously once the packing density reached above $52.0 \%$. The solid line in Fig. 3 represents the densification curve based on the shortest distance model of sintering. The model explains the feature of experimental result. However, the model has a discrepancy to the real structure of particle packing. In the model with low packing density, no contact between particles is assummed, which is not in accordance with the real particle packing. This discrepancy is reflected in the difference of the relative density between the model and the experimental result in the solid content range below $26 \%$ of the suspension.

Figure 5 shows the change in porosity of open and closed pores with densification of the YDC films. An important fea- 


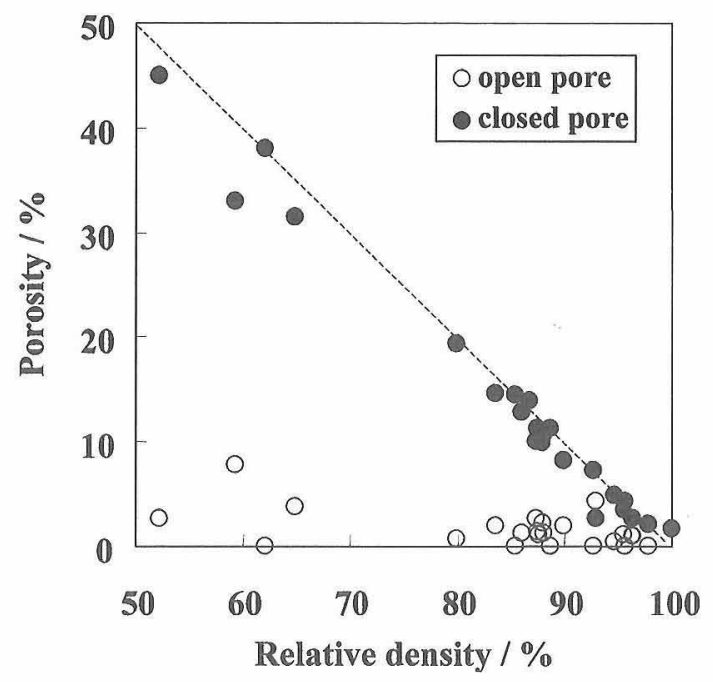

Fig. 5. Change in porosity of open and closed pores with densification of the YDC films.

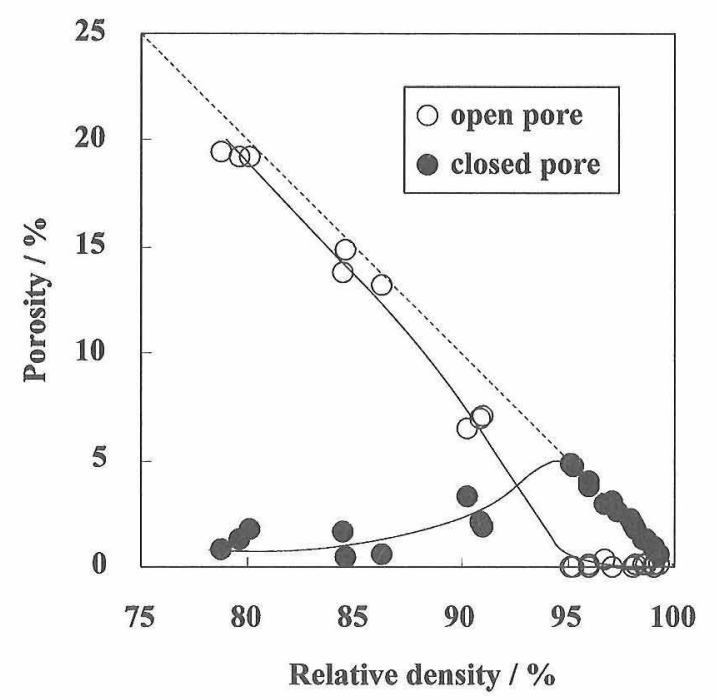

Fig. 6. Porosity of the YDC powder compacts formed by isostatic pressing (294 MPa) with densification.

ture with densification is the formation of closed pores in the poorly sintered films. As seen in Fig. 5, formation of open pores was suppressed in the films. The densification of the films proceeded through the disappearance of closed pores. This tendency of the densification was different from the usual powder compacts formed by isostatic pressing. Figure 6 shows the porosity of the YDC powder compacts formed by uniaxial pressing ( $49 \mathrm{MPa})$ followed by cold isostatic pressing (294 MPa).8) The green density was 60.9 $\%$ theoretical density and the sintering was carried out in air at $1600^{\circ} \mathrm{C}$. The open pores in the compacts disappeared at the relative density $95 \%$ and changed to closed pores. The final stage of sintering proceeded with the disappearance of closed pores. The comparison of the densification behavior between thick films (thickness $<500 \mu \mathrm{m}$ ) and powder compacts (thickness $\sim 2 \mathrm{~mm}$ ) indicates that (1) the densification process depends upon the sample thickness and (2) decrease in the thickness of powder compacts enhances the formation of closed pores.
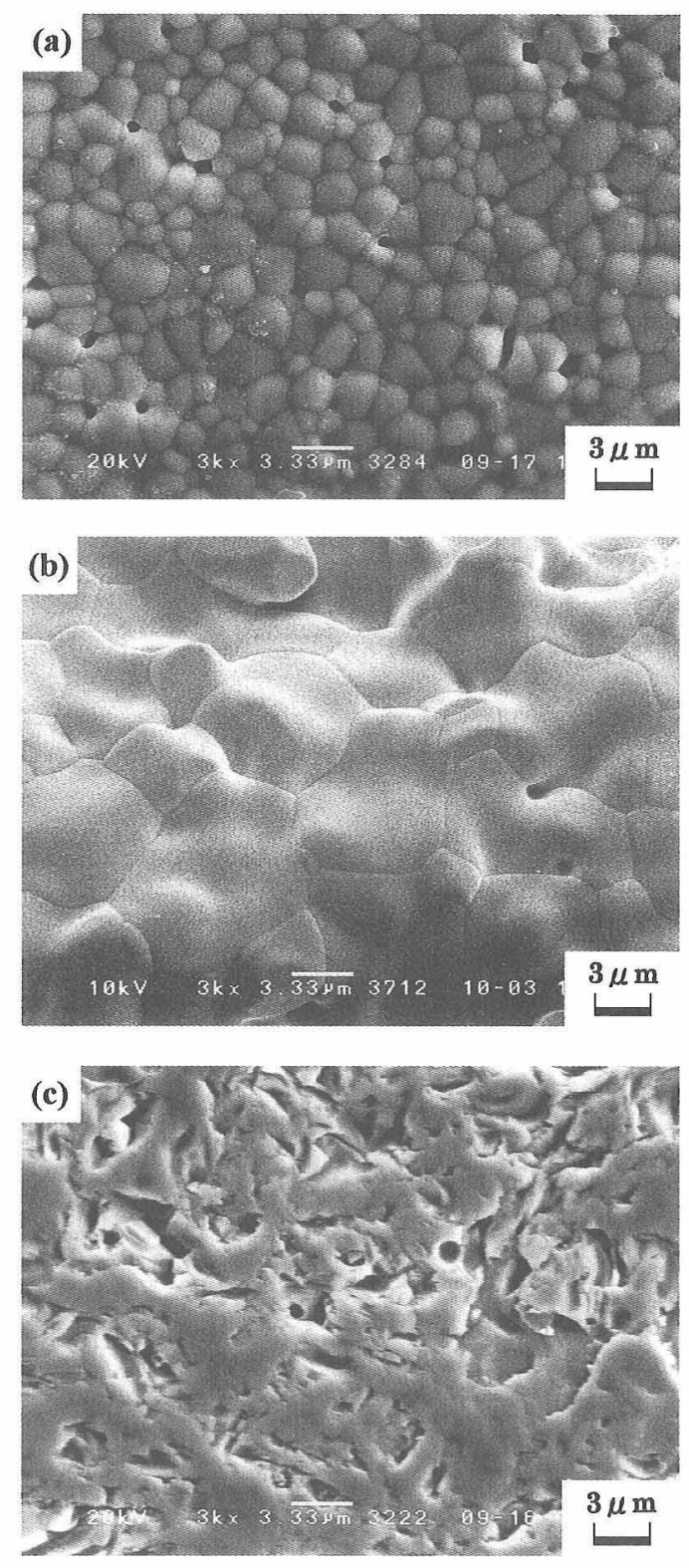

Fig. 7. Microstructures of (a) surface, (b) side and (c) cross section polished with $1 \mu \mathrm{m}$ diamond paste for the sintered YDC films, formed with 23.4 vol\% suspension.

\subsection{Microstructure}

Figures 7 and 8 show the microstructures of (a) surface, (b) side and (c) cross section polished with $1 \mu \mathrm{m}$ diamond paste for the sintered YDC films, formed with 23.4 and 30.5 vol\% suspensions, respectively. Although both the samples have the different density (Fig. 3), a similar feature was observed. The surface of the films consisted of $0.7-4.1 \mu \mathrm{m}$ grains. The pores on the surface in the low density sample (Fig. 7 (a)) were present at the grain boundaries, indicating the formation of open pores. The sides of the films were denser than the surface and little pore was observed. In addition, grain growth was more significant in the sides than in the surface. The microstructures of the cross section after the polishing were shown in Figs. 7(c) and 8(c), revealing the pore formation inside the films (closed pores). The feature of the above microstructural observation is interpreted with relation to the shrinkage of film by sintering (Fig. 9).

Figure 9 shows the shrinkage in the direction of $(O)$ 

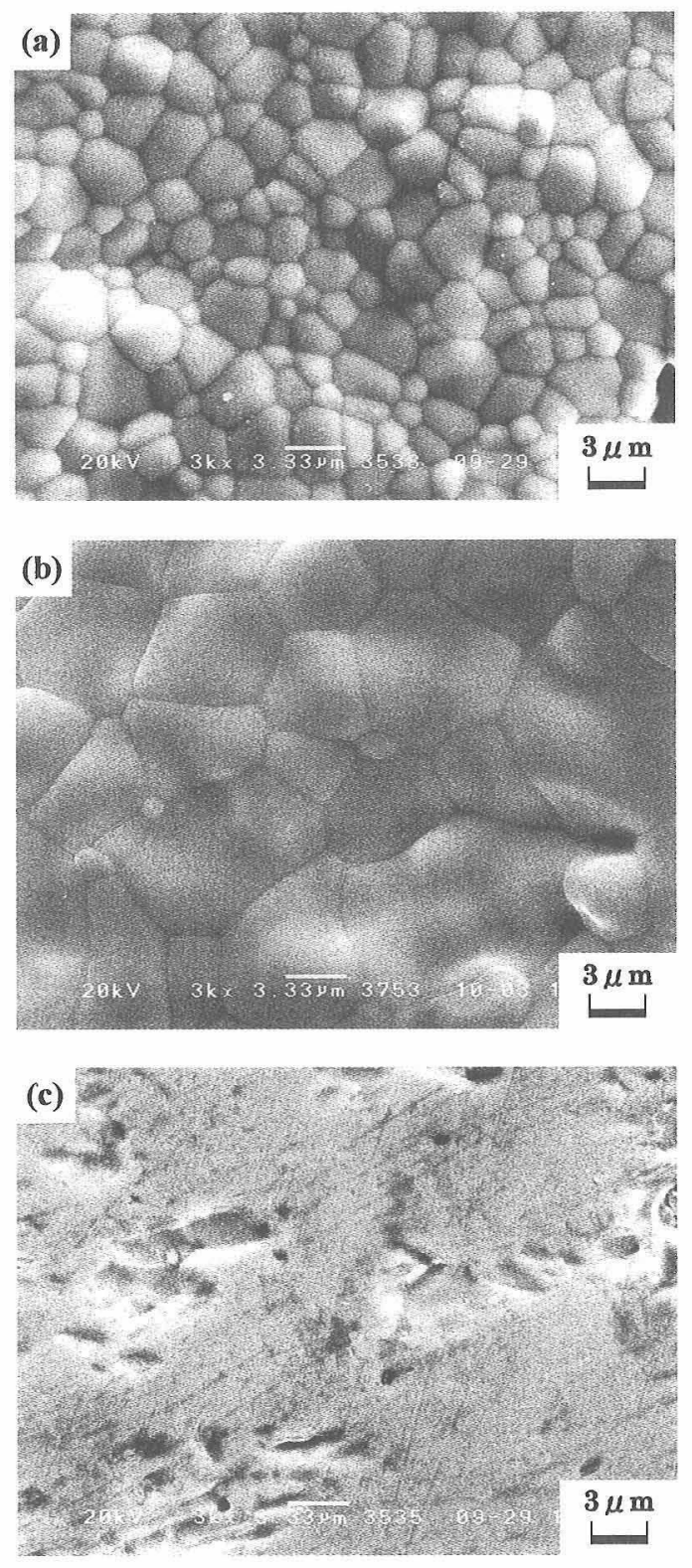

Fig. 8. Microstructures of (a) surface, (b) side and (c) cross section polished with $1 \mu \mathrm{m}$ diamond paste for the sintered YDC films, formed with $30.5 \mathrm{vol} \%$ suspension.

length and (O) thickness of YDC films after the sintering. The shrinkage was calculated by Eqs. (14) and (15) in the direction of length and thickness, respectively,

$$
\begin{aligned}
& \frac{\Delta l}{l_{1}}=\frac{l_{1}-l_{2}}{l_{1}} \\
& \frac{\Delta h}{h_{1}}=\frac{h_{1}-h_{2}}{h_{1}}
\end{aligned}
$$

where $l_{1}$ and $h_{1}$ represent the length and thickness of the green sheet before the sintering, and $l_{2}$ and $h_{2}$ are the length and thickness of the film after the sintering. The films shrunk more in the length than in the thickness. This result is associated with the density fluctuation in the dried green film. As described in Section 3.1, no shrinkage was measured in the direction of length during the drying of formed film. The increase of density with drying (Fig. 3) was due to the shrinkage in the direction of thickness. As a result,

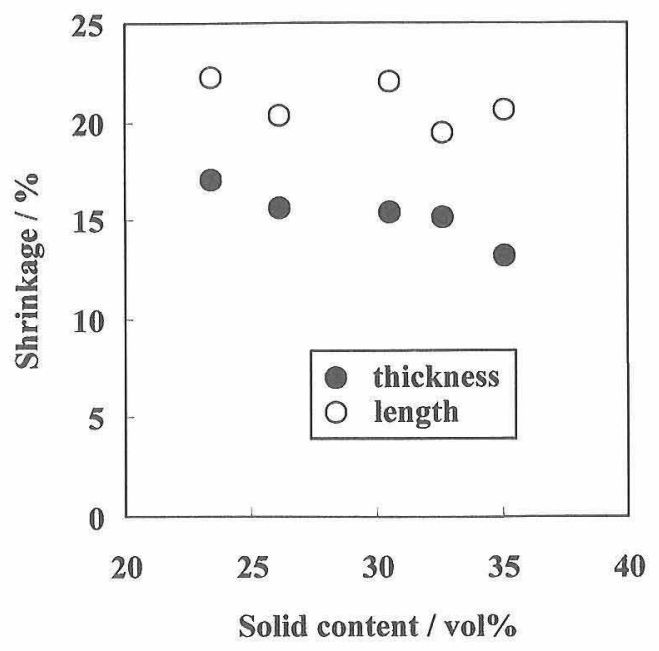

Fig. 9. Shrinkage in the direction of length $(O)$ and thickness (O) of YDC films after the sintering.

the packing density of powder becomes higher in the direction of thickness than in that of length. The higher packing density promotes the densification with lower shrinkage by sintering. That is, the densification of film became faster in the direction of thickness than in the direction of length. Furthermore, grain growth is promoted in the final stage of sintering. The faster densification in the direction of thickness leads to the higher degree of grain growth. The above microstructural feature associated with the density fluctuation proposes the piled structure of elongated grains along the direction of thickness. The large grains observed in the side of the films (Figs. 7(b) and 8(b)) correspond to the cross plane of the elongated grains. The side plane of the elongated grains is reflected in the microstructure consisting of small grains, observed on the surface of the films (Figs. $7(\mathrm{a})$ and $8(\mathrm{a})$ ).

\section{Conclusions}

(1) The thickness of YDC films, formed by doctor blade method of the pseudo-plastic aqueous suspensions of 23-35 vol\% solid, depended on the blade clearance and was independent of the concentration of the suspensions.

(2) The density of dried films bacame two times as high as the solid concentration of the suspension.

(3) The sinterability of the films was greatly dominated by the density of dried films (or concentration of suspension) and increased greatly when the dried density approached $60 \%$. This result was interpreted by the sintering model related to the shortest distance between particles in some particle packing structures.

(4) A lot of closed pores were formed in the heated films at the initial stage of sintering. The densification of the films proceeded through the disappearance of the closed pores.

(5) The densification rate and grain growth rate were higher in the direction of thickness than in that of length of the films.

\section{References}

1) Sridhar, S. and Pal, U. B., Powder Technology, 88, 173-78 (1996).

2) Curtis, C. L., Gawne, D. T. and Priestnall, M., J. Mater. Sci., 29, 3102-06 (1994).

3) Will, J., Mitterdorfer, A., Kleinlogel, C., Perednis, D. and Gauckler, L. J., Solid State Ionics, 131, 79-96 (2000). 
4) Huang, W., Shuk, P. and Greenblatt, M., Solid State Ionics, 100, 23-27 (1997).

5) Sasaki, H., Otoshi, S., Suzuki, M., Sogi, T., Kajimura, A., Sugiura, N. and Ippommatsu, M., Solid State Ionics, 72, 253-56 (1994)

6) Mistler, R. E., Am. Ceram. Soc. Bull., 77, 82-86 (1998).

7) Tagawa, H., "SOFC and Environment of Earth," Agune Shohu Publishing Inc., Tokyo (1998) pp. 118-31.

8) Higashi, K., Sonoda, K., Ono, H., Sameshima, S. and Hirata, Y., J. Mater. Res., 14, 957-67 (1999).

9) Hirata, Y., Ono, H., Higashi, K., Sonoda, K. and Sameshima,
S., Ceramic Transactions, 92, 137-48 (1999).

10) Corso, G., Casto, S. L., Lombardo, A. and Freni, S., Materials Chemistry and Physics, 56, 125-33 (1998).

11) Pitchumani, R. and Karbhari, V. M., J. Am. Ceram. Soc., 78, 2497-503 (1995).

12) Seno, H., Minami, Y. and Wakino, K., "New Ceramic Powder Hand Book," Scienceforum, Tokyo, Ed. by Kato, T. and Yamaguchi, T. (1983) pp. 350-52.

13) Hirata, Y., Aksay, I. A. and Kikuchi, R., J. Ceram. Soc. Japan, 98, 126-35 (1990). 